\title{
Panel Data Analysis: the Influence of Climatic Variables on Medicines Sales in Southern Brazil
}

\section{Análise de Dados em Painel: a Influência das Variáveis Climáticas na Venda de Medicamentos na Região Sul do Brasil}

\author{
Pedro Brandão Dalla Valle \\ Flávio Tosi Feijób
}

\begin{abstract}
This paper proposes a model for the analysis of the impact of climatic variables on medicines sales in the southern region of Brazil. For this study, sales data of 262 pharmacies were collected, representing more than 80 million commercial transactions, and meteorological data from 26 cities through the national institute of meteorology during the period of January 2012 and June 2016. Using the fixed-effects panel data model, a methodology characterized by the combined use of time series and cross-sections, it is estimated that the variables with the greatest influence on sales are temperature and precipitation. The main hypothesis tested in this study, that climatic variables have a significant effect on sales, could be confirmed for some categories of medicines, with different influences between them.
\end{abstract}

Keywords: Retail. Climate. Drugstore. Sales. Econometrics.

Resumo: Este artigo propõe a construção de um modelo econométrico para a análise do impacto das variáveis climáticas sobre a venda de medicamentos. Para isso, foram coletadas informações de venda de 262 farmácias da região Sul do Brasil, representando mais de 80 milhões de transações comerciais, durante o período de janeiro de 2012 a junho de 2016. Os dados foram combinados com as informações meteorológicas de 26 cidades, disponibilizadas pelo Instituto Nacional de Meteorologia. Utilizando um modelo de dados em painel por efeitos fixos, que combina o uso de séries temporais e cortes transversais, é possível estimar que as variáveis climáticas com maior influência nas vendas de medicamentos são temperatura e a precipitação . A principal hipótese testada neste estudo, de que as variáveis climáticas têm um efeito significativo nas vendas, pôde ser confirmada para algumas categorias de medicamentos, com diferentes intensidades entre elas.

Palavras-chave: Varejo. Clima. Farmácia. Vendas. Econometria.

JEL Classification: D220.

a Universidade do Vale do Rio dos Sinos (UNISINOS), Escola de Gestão e Negócios, Programa de Pós-Graduação em Administração. Porto Alegre, Rio Grande do Sul, Brasil.

b Universidade Federal do Rio Grande do Sul (UFRGS), Faculdade de Ciências Econômicas (FCE), Departamento de Economia e Relações Internacionais (DERI). Porto Alegre, Rio Grande do Sul, Brasil. 


\section{Introduction}

Over the last years, advances in the health care have brought benefits for all, however, this progress has been accompanied by a significant increase in costs and a growing demand for the purchase of medicines. Increase knowledge about this market and tends to generate a more efficient allocation of available resources and provide economic gains for patients, the pharmaceutical industry, retail and the whole society. In this article, the main objective is to analyze the impact of climatic variables on medicines sales in the southern Brazil during the period of January 2012 and June 2016. For this, sales data were collected through 262 pharmacies in the region, representing more than 80 million commercial transactions, and meteorological data from 26 cities, made publicly available by the National Institute of Meteorology (INMET).

According to Barros (1995), on the one hand, access to medicines is a right of the population, on the other, resources are limited. It is therefore necessary to share knowledge and responsibilities on the subject, promoting the efficient allocation of available resources and minimizing costs. For Brito and Barros (2015), the waste of medicines reaches $20 \%$ of everything that is acquired in retail, hospitals or by the public power in Brazil. Among the several reasons for the high waste of drugs, there is a lack of technical and scientific criteria in the acquisition of medicines by several sectors (public and private) of society, without a mapping of seasonality or any other effects that affect the demand of this segment.

A market or pharmacy was just a place where buyers and sellers gather to buy and sell their products. Today, according to Kotler and Keller (2006), it is possible to describe these stores as a set of buyers and sellers who transact a particular type of product or service. In this scenario, companies act to stimulate interest in their own products, to achieve the organization's goals. For Bernanke (2009), the demand of a market is associated with the rational allocation of consumer income between different products, and for medicines there is no difference, pharmacies compete against each other for the limited resources available in the Market.

Everyone seeks to understand the demand and which elements can affect it, among others, the following may be considered: desires and needs of individuals; purchasing power; availability of services; complementary or substitute products; opportunity costs. Looking at the drug market, it is easy to see how individuals' needs can easily influence market demand, an outbreak of flu will increase the demand for flu medicines, syrups and tissues. The same is true for purchasing power and service availability, shifting demand up or down. Complementary and substitute products can act as an opportunity for the segment when well exploited or become a threat if not mapped in time. Finally, opportunity cost involves all the effort expended for the customer to make a purchase. 


\section{Literature Review}

Climate related issues have been widely discussed in the most diverse areas of study since the United Nations Conference on the Human Environment in 1972, when leaders from major countries met to discuss the global environmental degradation. Since then, many researchers try to measure the effects of climate on the economy.

In a study presented by Solomou and Wu (1999), the effect of climate on agricultural production in Germany, France and the United Kingdom over a period of 60 years is analyzed. For the authors, climate is responsible for two thirds of the variation in agricultural production in the region. Richard Tol (2000) analyzed the impact of climate change on water and energy consumption, tourism and agricultural productivity in the Netherlands. Among other findings, the study points out that a long period of pleasant weather stimulates domestic tourism in the same year and international tourism the following year. The same study also indicates that water consumption increases considerably during hot days, but does not change significantly over long periods of dry weather.

Margulis (2010) points that climate change in Brazil may cause a reduction between $0.5 \%$ and $2.3 \%$ in GDP by 2050 . Electricity production would also be affected; in the northeast, decreasing rainfall may cause a reduction in hydroelectric power generation, affecting production capacity by approximately $30 \%$ by 2100 . In agriculture, the main crops, except for sugarcane, may suffer yield reduction in the coming years, especially soybeans (32\%), corn (15\%) and coffee (18\%). In contrast, Camargo et al (1986) analyzes soybean production in the state of São Paulo and cites the thermal factor as indicative of the choice of the product to be cultivated, as well as the variable factors related to scarcity or excess rainfall. This case indicates that the ability to accurately predict climate phenomena can prevent such losses from directly impacting business.

The north American economist Veblen (1899) was the first to note that the rational economic behavior of individuals may be influenced by psychological effects. According to the author, fear and social status are variables capable of influencing the consumption pattern of individuals. More recently, Mason, Mayer and Wilkinson (1993), indicate that consumer behavior is influenced by the following factors: Economy, climate, demography, seasonality, market trends and the marketing compound.

Climate-related variables also appear for Levy (2012), the author shows that in the United States, during the hurricane season, many families are preparing for the phenomenon by stocking bottles of water, plywood, batteries, generators and food in general. The author also points out that it is common for large companies to use climate forecasts to plan delivery times, promotions and discounts. Complementarily, Levy also mentions that during cold or rainy periods supermarkets tend 
to sell less meat, but on warmer days, a temperature increase of $7^{\circ} \mathrm{C}$, for example, triples meat sales and increases consumption of lettuce by $50 \%$.

The first researcher to study the impact of climatic variables on retail consumption was Steele (1951), the author still notes that previously some studies had already published from the perspective of energy and agricultural production areas. Steele's study correlated precipitation, wind, temperature, and snow with sales at department stores in the United States between 1940 and 1948. The result indicates that cold, rain and snow are variables that reduce overall sales according their intensities, with temperature being the most relevant coefficient. The reduction in consumption was attributed to the following main reasons: Discomfort to visit the store, consumers physically avoid bad weather conditions, psychological effects and lesser merchandising appeal.

For Starr-Mccluer (2000), climate variables can influence individuals' buying behavior in three ways: Climate can make shopping experience easier or harder; The climate complements a number of outdoor recreational activities; Some goods complement climate-related activities. To conclude this chapter, Larsen (2006) considers that it is obvious that climatic variables exert an effect on the demand for products. Even if its full size is not yet known, the author believes that if climate predictions improve in the future, it will be possible to help companies and individuals better plan their spending and investments in an uncertain climate environment.

\section{Methodology}

To solve this theoretical gap, the research proposes a regression method to identify the influence of weather on medicines sales. A regression is a statistical technique used to measure the interference of one or more independent variables in a dependent variable, allowing to estimate a straight equation where it is possible to obtain results of the dependent variable by changes in the independent variable and has the purpose of estimating the relationship between two quantities and the relationship between the independent and dependent variables. The most widely used estimation method is that of ordinary least squares, which seeks to minimize the sum of the squares of the vertical distances of each point of the sample in relation to the estimated line.

Gujarati and Porter (2011) indicates that three types of data can be used for applied analysis: Time series, cross sections and data panels. In time series, data of one or more variables are observed over time, in cross section the data are related to one or more variables for several sample units, since the use of panel data allows to explore together the variations along of time and different units or individuals. This last one methodology can be characterized by the combined use of time series and cross-sections, thus allowing a more complete and efficient estimation of the 
econometric models. It should be remembered that the estimation of panel models becomes more complex due to the heterogeneity of individuals, such as different economic structures between cities or regions.

As climatic conditions and sales have different behaviors for each region observed and also over the time, it wouldn't be possible to construct a regression through simple time series or a cross-sections models. The solution found was to use a panel data model, allowing a complete and efficient estimation. So this study follows a model for panel data presented by Hendry (1995) that suggests the exposes of the main theory or hypothesis, specification of the mathematical model of the theory and the econometric model, estimation of the parameters and the hypothesis testing. Given the literature review, which indicates that the weather conditions can influence the pattern of consumption in several areas, and the main hypothesis that includes the sale of medicines in this context, it is possible to suggest a preliminary equation, where is the estimated sale of medicines, the constant and is the vector of variable $X$ of the individual.

$$
\mathrm{Y}_{i}=\beta_{0}+\gamma \mathrm{X}_{\text {in }}
$$

Soon it is possible to include the climate variables and sales history on the same structure, where is the coefficient of the average individual sales, is the coefficient for average individual temperature and is the coefficient of individual accumulated precipitation. The signs (positive or negative) follow a preliminary data analysis, that indicate lower sales in periods of low temperature or heavy rainfall.

$$
\mathrm{Y}_{i}=\beta_{0}+\gamma \mathrm{As}_{i}+\delta \text { Temp }_{i}-\varepsilon \operatorname{Prec}_{i}
$$

Several other variables, which could not be measured in this study, can influence the outcome of the proposed model. For the model to consider inaccurate relationships over variables, the unobserved effect will be defined in the equation three by .

$$
\mathrm{Y}_{i}=\beta_{0}+\gamma \mathrm{As}_{i}+\delta \operatorname{Temp}_{i}-\varepsilon \operatorname{Prec}_{i}+\mathrm{u}
$$

When working with a regression model in panel data, there are some estimation techniques that can be considered, in this paper the effects were tested in three econometric models: Pooled, Fixed Effects and Random Effects. In order to determine the most appropriate model, there are three hypotheses that should be tested through the tests of Chow, Breusch-Pagan and Hausman. After determining 
the estimation model, the effects of cross section ${ }^{1}$ should be added in the main equation represented by whose $i$ is the individual and $t$ is time period for the previously defined variables.

$$
\mathrm{Y}_{i t}=\beta_{0}+\gamma \mathrm{As}_{i t}+\delta \mathrm{Temp}_{i t}-\varepsilon \operatorname{Prec}_{i t}+\mathrm{E}_{\mathrm{CSit}}+\mathrm{u}
$$

With mathematical and statistical models defined, data is required to find numerical values. Two main sources of data were used is this case, the first one, medicines sales were collected through 262 pharmacies in southern Brazil during the period five years, representing more than 80 million transactions and providing a high statistical robustness. In order to bring a deeper analysis, the database were segmented into 19 categories as presented in table 1 .

Per second, the climatic data were obtained through the national institute of meteorology, an agency of the ministry of agriculture, livestock and supply, whose objective is to provide meteorological information to the Brazilian society and assist in the decision-making process in multiple areas. It can be observed several types of variables such as temperature, humidity, wind speed and direction, atmospheric pressure and precipitation. During the preliminary analysis, precipitation and temperature were the only selected variables, ensuring the best statistical consistency to the model.

After collecting data from the two sources of research, it was necessary to cross the both bases and create a single panel. Joining the two databases, it was found that the transactional base segments the information through cities while the meteorological information was segmented by regions, since there are no meteorological stations for all cities. Thus, 12 regions were defined to represent 26 cities.

Table 1 - Medicine categories

\begin{tabular}{ll}
\hline Treatment & Description \\
\hline Allergies & $\begin{array}{l}\text { Antiallergic, antiasthmatics, dermatitis and dermatoses, antibiotics, } \\
\text { corticosteroids and antiviral medicines }\end{array}$ \\
Cholesterol & Medicines for cholesterol and triglyceride reduction \\
Contusion & Analgesics, anti-inflammatories, muscle relaxants and arthrosis medicines \\
Diabetes & Antidiabetics, insulin and glucose meters \\
Headache & Paracetamol, Dipyrone, Ibuprofen and Acetylsalicylic Acid \\
Weight loss & Reducing appetite and weight loss \\
Gastrointestinal & Medications for the treatment of ulcers, herbal medicines, antacids, \\
Flu & verminoses, nausea, diarrhea, digestive and laxatives \\
Oncology & Antipyretics, anti-fluids, decongestants and expectorants \\
\hline
\end{tabular}

Continua...

1 The cross-sectional effects are used to represent the distinct behavior among the individuals over the variables, in this case different regions. 
Conclusão.

\begin{tabular}{ll}
\hline Treatment & Description \\
\hline Skin & Medicines for treatment of acne, rashes, healing, mucous and galderma \\
Women's Health & Contraceptives, menopause, vaginal creams, pregnancy test, uterine relaxant \\
Men's Health & $\begin{array}{l}\text { Medicines for treatment of erectile dysfunction, prostate, hair loss and } \\
\text { hormones }\end{array}$ \\
Heart System & Antihypertensive, cardiovascular and diuretic medicines \\
Circulatory system & Medicines for treatment of circulatory disorders, thrombosis and anti-vertigo \\
Nervous system & Treatment of depression, convulsion, antipsychotics, tranquilizers, Alzheimer's, \\
Blood System & Parkinson's disease and brain disorders medicines \\
Endocrine & vasodilators, adrenergic inhibitors, antihypertensives \\
Optician & Hormone treatment, hyperthyroidism, hypothyroidism \\
Vitamins & Medicines for treatment of glaucoma, lubricant and pupil dilator \\
\hline
\end{tabular}

Source: Prepared by the authors (2021).

After collecting data from the two sources of research, it was necessary to cross the both bases and create a single panel. Joining the two databases, it was found that the transactional base segments the information through cities while the meteorological information was segmented by regions, since there are no meteorological stations for all cities. Thus, 12 regions were defined to represent 26 cities.

A descriptive analysis of transactional and climatic data is presented in table 2. The first data indicate the total sale of medicines over one week of each commercial establishment observed in the region. The total amount of precipitation is evaluated in relation to the vertical depth of water on a horizontal projection of the soil surface, being considered in this study the total precipitation recorded during a week for each region. Values close to zero indicate the absence of rain during the period and represents the minimum precipitation for all regions, the recorded mean was $35 \mathrm{~mm}$ while the maximum values reach up to $334 \mathrm{~mm}$ in a single week. Different from the previous variables, for temperature is considered the average value observed over seven days for each of the regions. 


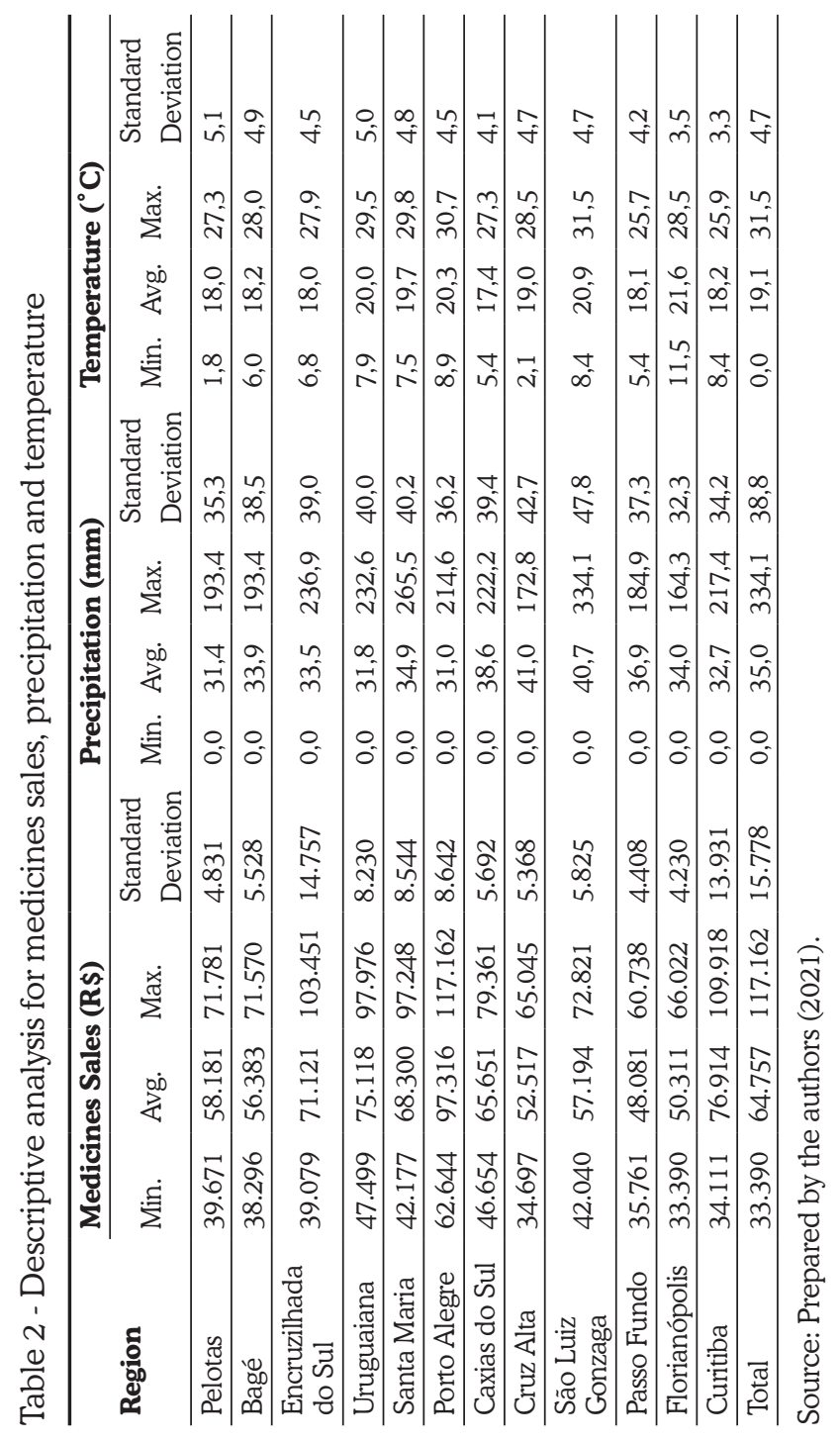


To reduce the effect of price increases, financial values were deflated according to the national consumer price index, released by the Brazilian Institute of Geography and Statistics based on January 2019.

\section{Result Analysis}

As a first step, to determine the most appropriate model of analysis of results, Chow, Breusch-Pagan and Hausman tests were performed. The Chow test, which compares the least squares group method with the fixed effects model, showed $\mathrm{p}$-value less than 0.05 , indicating that the fixed effects model would be the most adequate. The Breusch-Pagan test, which confronts the least squares group with random effects model, also presented a low p-value $(0,0266)$, indicating that between these two models, the use of random effects would be the most appropriate. Finally, the Hausman test compared the two models with the best result, indicating that the best fit model was the fixed effects model, since p-value was zero.

Table 3 - Chow, Breusch-Pagan and Hausman tests analysis

\begin{tabular}{lccc}
\hline Test & Comparative & P-Value & Interpretation \\
\hline Chow & Pooled or fixed effects & 0,0000 & Fixed effects \\
\hline Breusch-Pagan & Pooled or random effects & 0,0266 & Random effects \\
\hline Hausman & Fixed or random effects & 0,0000 & Fixed effects \\
\hline
\end{tabular}

Source: Prepared by the authors (2021).

With the definition of the fixed effects model as the most adequate, the objective now is to present the main results found throughout this study, identifying the relationship between climatic variations and a possible change in the pattern of medicines sales. The first analysis represents the total weekly sale of medicines, the result observed in table 4 indicates through $\mathrm{R}^{2}$ statistic that $85.96 \%$ of sales can be explained through the model, prob demonstrates a high level of significance for both variables (precipitation and temperature) while prob $f$ a high level for model significance, and Durbin Watson test indicates the absence of autocorrelation.

Table 4 - Total sale of medicines

\begin{tabular}{ll|l|l|l|l|l|l|l|l}
\hline \multicolumn{1}{c}{ Coefficient } & \multicolumn{4}{l}{ Statistic } \\
\cline { 2 - 7 } & Constant & Avg. Sale & Precipitation & Prob. & $\begin{array}{l}\text { Avg. } \\
\text { Temp. }\end{array}$ & Prob. & $R^{2}$ & Prob. F & $\begin{array}{l}\text { Durbin } \\
\text { Watson }\end{array}$ \\
\hline $\begin{array}{l}\text { Total } \\
\text { Medicines }\end{array}$ & $26.342,04$ & 0,6520 & $-14,49$ & 0,0000 & $-171,53$ & 0,0000 & $85,96 \%$ & 0,0000 & 2,26 \\
\hline
\end{tabular}

Source: Prepared by the authors (2021).

Still in the same view, it is possible to observe simultaneous correlation between precipitation and temperature on estimated medicines sales. Regarding the 
negative coefficients observed, the interpretation is that an increase in the values of any variables should represent that the sale should be lower. More specifically, for each millimeter of rain it is estimated a reduction of $R \$ 14,49$ in sales, meanwhile an increase in average temperature by $1^{\circ} \mathrm{C}$ will mean a reduction of $R \$ 171,53$. To display the effects of climatic variables acting simultaneously, a three-dimensional surface chart is used, as can be seen in Figure 1. As both precipitation and temperature have negative effects, it is possible to observe that the graph reaches its highest value exactly at the minimum historical point of these two variables $(0 \mathrm{~mm}$ and $\left.1.8^{\circ} \mathrm{C}\right)$.

Figure 1 - Weekly sale of medicines

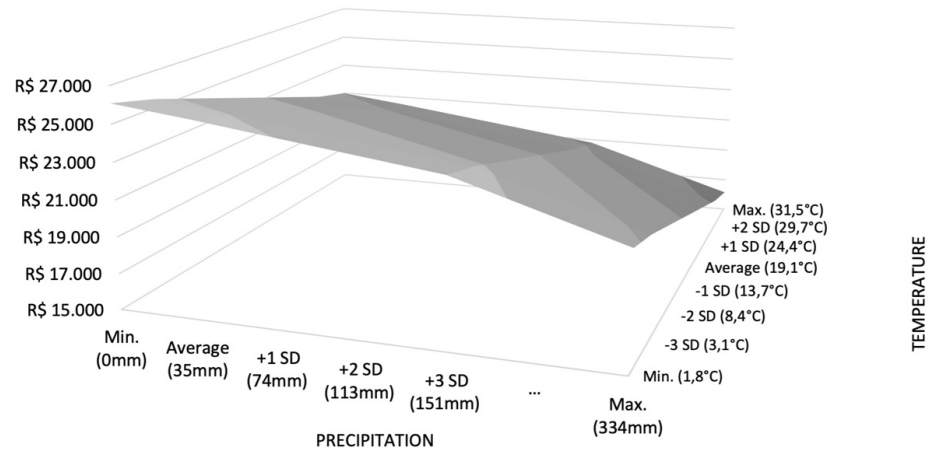

Source: Prepared by the authors (2021).

For further analysis, the panel was segmented into 19 categories of medicines and the regression model was applied again to each of them. The objective this time is to observe the individual behavior of each type of treatment and how the climate variables may provide a distinct influence. Among all categories analyzed, only eight presented simultaneous correlation for both variables, the results can be observed in table 5. Although for precipitation the effect is the same as found for the general model (with differences only in intensity), for temperature only medicines for allergies, headache, flu and vitamins showed negative correlation. Treatments for contusion, blood system, optician and skin exhibited the opposite behavior, where sales grow with increasing temperature. 
Table 5 - Medicines with simultaneous correlation

\begin{tabular}{|c|c|c|c|c|c|c|c|c|c|}
\hline & \multicolumn{6}{|c|}{ Coefficient } & \multicolumn{3}{|c|}{ Statistic } \\
\hline & Constant & Avg. Sale & Precipitation & Prob. & $\begin{array}{l}\text { Avg. } \\
\text { Temp. }\end{array}$ & Prob. & $\mathrm{R}^{2}$ & Prob. F & $\begin{array}{l}\text { Durbin } \\
\text { Watson }\end{array}$ \\
\hline Allergies & $4.347,76$ & 0,6203 & $-2,2884$ & 0,0000 & $-84,2953$ & 0,0000 & $78,71 \%$ & 0,0000 & 2,3308 \\
\hline Headache & $3.301,32$ & 0,5682 & $-1,8300$ & 0,0000 & $-14,1488$ & 0,0000 & $82,26 \%$ & 0,0000 & 2,2162 \\
\hline Flu & $1.944,68$ & 0,7546 & $-0,0347$ & 0,0000 & $-2,3518$ & 0,0000 & $91,84 \%$ & 0,0000 & 1,3600 \\
\hline Vitamins & $1.413,13$ & 0,5134 & $-0,4363$ & 0,0206 & $-3,6436$ & 0,0235 & $74,42 \%$ & 0,0000 & 2,2025 \\
\hline Contusion & 231,75 & 0,4729 & $-0,1167$ & 0,000 & 5,9173 & 0,0000 & $72,82 \%$ & 0,0000 & 2,1877 \\
\hline Blood System & 291,02 & 0,0601 & $-0,0790$ & 0,0454 & 1,4012 & 0,0000 & $39,14 \%$ & 0,0000 & 2,0187 \\
\hline Optician & $1.044,05$ & 0,4281 & $-0,5239$ & 0,0000 & 3,6000 & 0,0010 & $79,55 \%$ & 0,0000 & 2,1803 \\
\hline Skin & $2.411,79$ & 0,1729 & $-0,7817$ & 0,0027 & 11,6878 & 0,0000 & $60,38 \%$ & 0,0000 & 2,0491 \\
\hline
\end{tabular}

Source: Prepared by the authors (2021).

Starting with allergy medicines, the first category individually analyzed, their results show the same behavior of the general model. It is estimated that $78,71 \%$ of the weekly sales can be explained through the model with a significance level of $1 \%$. For each millimeter of rain it is estimated a reduction of $R \$ 2,28$ in sales, meanwhile an increase in average temperature by $1^{\circ} \mathrm{C}$ will mean a reduction of $\mathrm{R} \$$ 84,29 . With one of the largest amplitudes between the minimum and maximum points of the chart (Figure 2), it is possible to observe a high intensity of the effects of climate variables on the demand of this product category. Probably the incidence of allergy-related health problems is higher in dry and cold weeks, increasing the consumption of this type of medicine during these periods.

Figure 2 - Weekly sale of allergies medicines

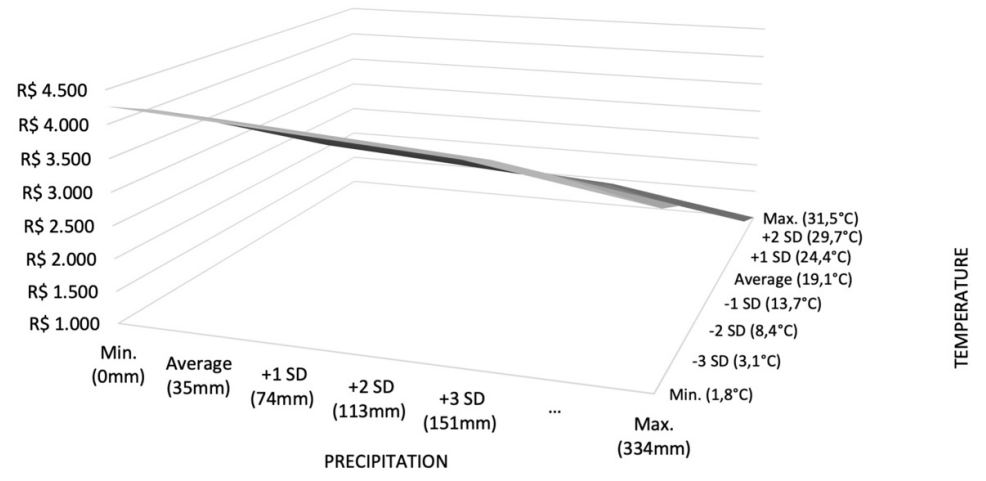

Source: Prepared by the authors (2021).

The behavior observed for headache medications is very similar to allergies and the general model, but with a lower intensity. It is estimated that $82,26 \%$ of the weekly sales can be explained through the model with a significance level of $1 \%$. 
For each millimeter of rain it is estimated a reduction of $\mathrm{R} \$ 1,83$ in sales, meanwhile an increase in average temperature by $1^{\circ} \mathrm{C}$ will mean a reduction of $\mathrm{R} \$ 14,14$. Even with a smaller amplitude (Figure 3), it is still possible to observe a significant impact of climate variables in this category demand.

Figure 3 - Weekly sale of medicines for headache

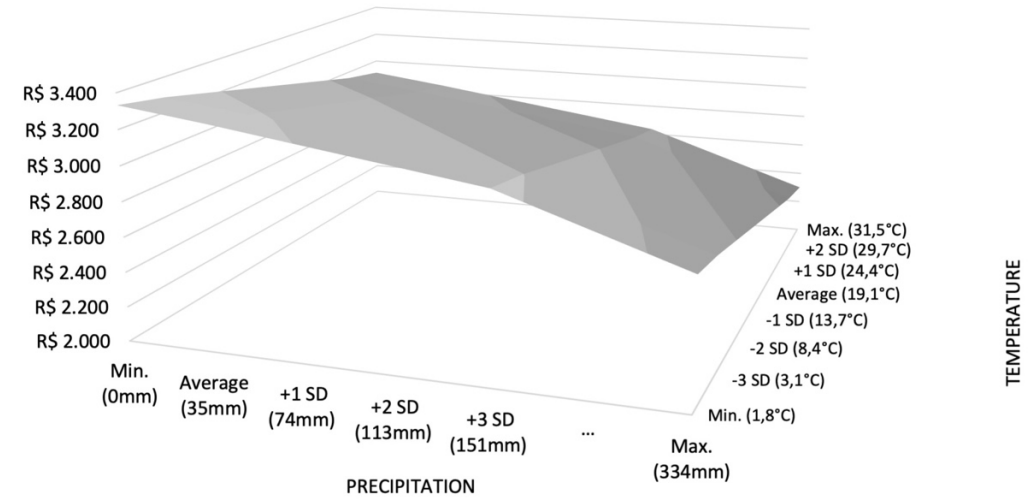

Source: Prepared by the authors (2021).

The category of flu medicines also presented similar behavior to the others presented so far, proving the empirical knowledge that people are more prone to flu in cold weather. It is estimated that $91,84 \%$ of sales can be explained through the model with a significance level of $1 \%$. Although the model is statistically significant, the climate impact on the model is smaller (Figure 4), for each millimeter of rain it is estimated a reduction of just $R \$ 0,03$ in sales, meanwhile an increase in average temperature by $1^{\circ} \mathrm{C}$ will mean a reduction of $R \$ 2,35$. One possibility for the low observed effect is the changed value for the DW test, where it is not possible to prove the absence of autocorrelation to the model.

Figure 4 - Weekly sale of medicines for flu

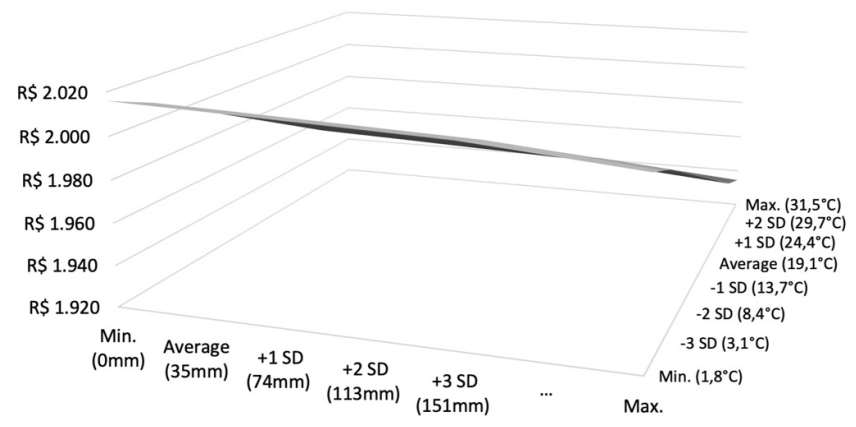

Source: Prepared by the authors (2021). 
Vitamins is the last category with similar results (Figure 5), for each millimeter of rain it is estimated a reduction of $R \$ 0,43$ in sales, meanwhile an increase in average temperature by $1^{\circ} \mathrm{C}$ will mean a reduction of $R \$ 3,64$. Just $74,42 \%$ of the weekly sales can be explained through the model with a significance level of $5 \%$. Less relevance of vitamins in the general context of a pharmacy may explain the model's difficulty in representing total sales.

Figure 5 - Weekly sale of vitamins

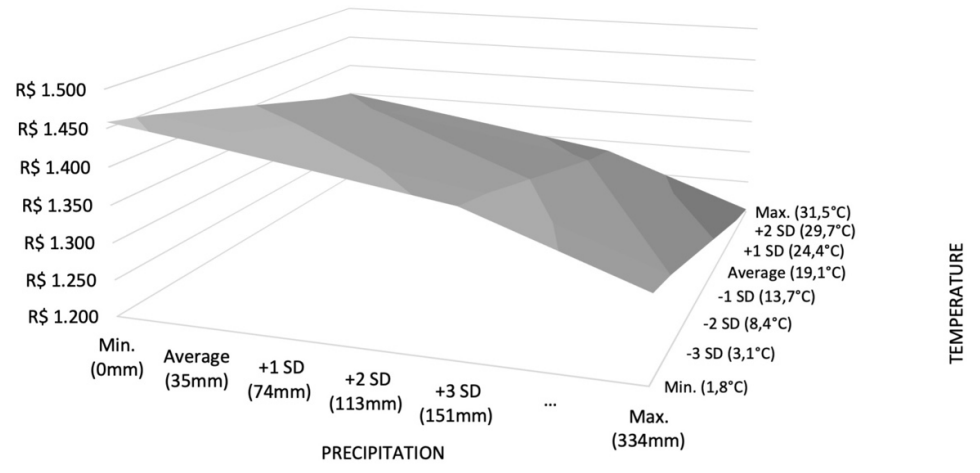

Source: Prepared by the authors (2021).

From medicines for contusion it is possible to observe a different behavior of temperature in the model, now having a positive effect on sales. It is estimated that $72,82 \%$ of the weekly sales can be explained through the model with a significance level of $1 \%$, where for each millimeter of rain it is estimated a reduction of $R \$ 0,11$ in sales, meanwhile an increase in average temperature by $1^{\circ} \mathrm{C}$ will mean a gain of $\mathrm{R} \$ 5,91$. The increased demand for bruising treatment in hot weeks can be seen in Figure 6 and could be justified by summer sports or different activities that we do in those periods. 
Figure 6 - Weekly sale of medicines for contusion

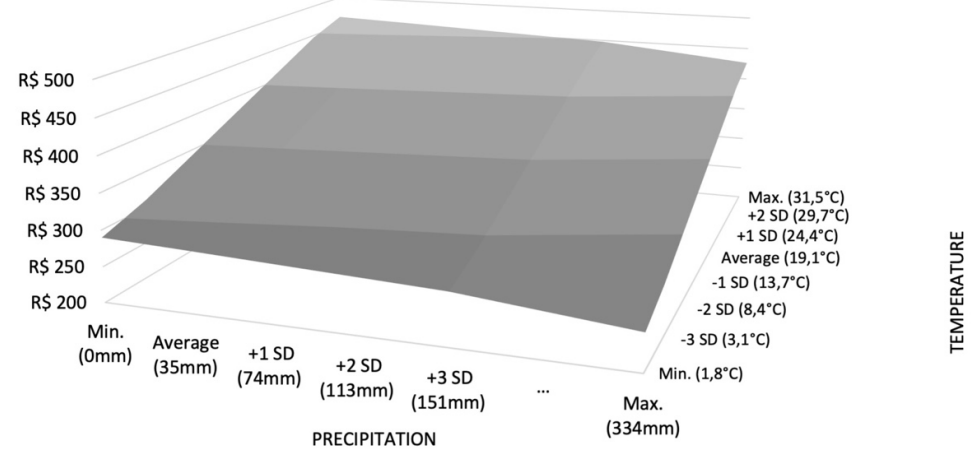

Source: Prepared by the authors (2021).

Blood system medicines (Figure 7) have the lowest percentage of the model's ability to explain their sales, just $39,14 \%$. Still, the model is significant at a $5 \%$ level, where for each millimeter of rain it is estimated a reduction of $R \$ 0,07$ in sales, meanwhile an increase in average temperature by $1^{\circ} \mathrm{C}$ will mean a gain of $R \$ 1,40$.

Figure 7 - Weekly sale of medicines for blood system

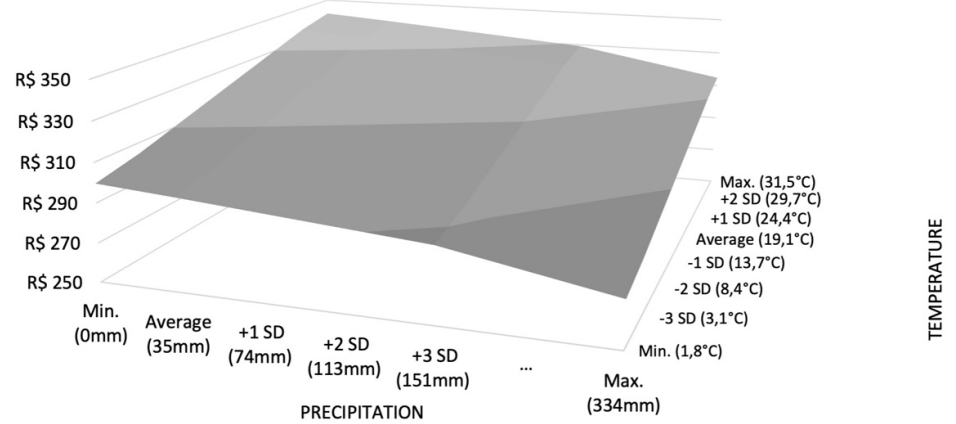

Source: Prepared by the authors (2021).

The category of opticians is basically made up of medicines for the treatment of glaucoma, lubricants and dilators and pupils, its behavior can be observed in figure 8 . It is estimated that $79,55 \%$ of sales can be explained through the model with a significance level of $1 \%$, where for each millimeter of rain it is estimated a reduction of $R \$ 0,52$ in sales, meanwhile an increase in average temperature by $1^{\circ} \mathrm{C}$ will mean a gain of $\mathrm{R} \$ 3,60$. 
Figure 8 - Weekly sale of optcian medicines

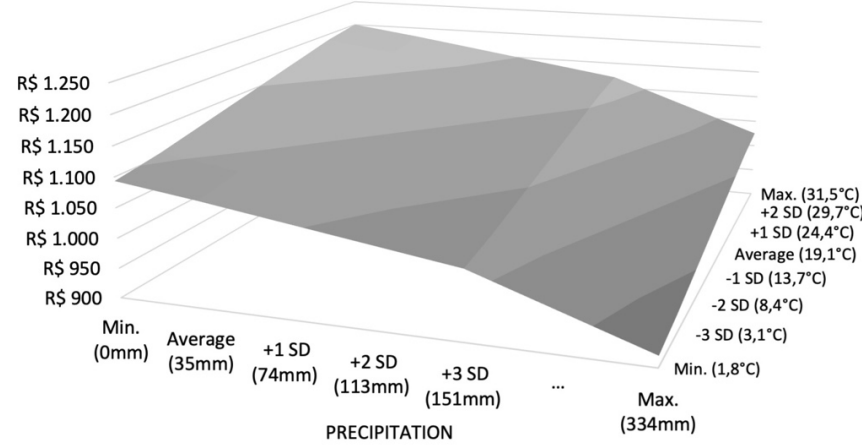

Source: Prepared by the authors (2021).

Medicines for skin care are the last category to show simultaneous correlation to both climatic variables, where $60,38 \%$ of sales can be explained through the model with a significance level of $1 \%$. For each millimeter of rain it is estimated a reduction of $R \$ 0,78$ in sales, meanwhile an increase in average temperature by $1^{\circ} \mathrm{C}$ will mean a gain of $\mathrm{R} \$ 11,68$. A increased sun exposure in hot weather may justify the increased demand for such treatments.

Figure 9 - Weekly sale of medicines for skin

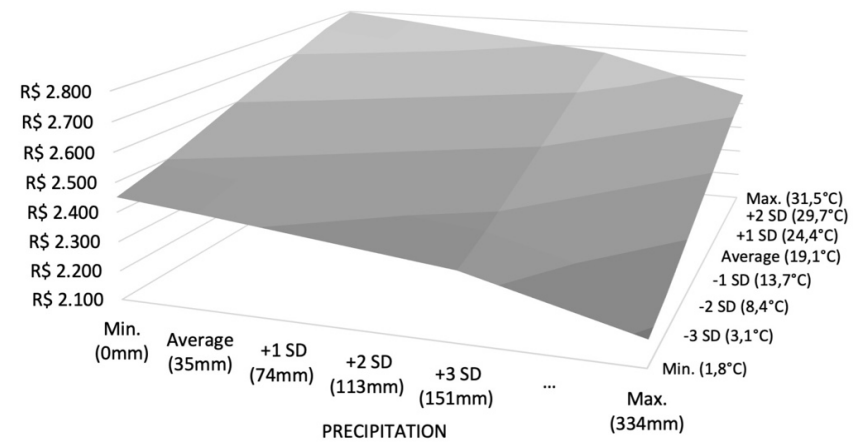

Source: Prepared by the authors (2021).

From this moment, all categories were not statistically significant to validate simultaneous correlation, so they are individually tested for each climate variable. In this context, four categories showed a significant correlation of temperature over sales, as can be seen in Table 6 . Nervous and circulatory system medicines were validated from prob statistics at $1 \%$ significance, being the first model able to explain $82,16 \%$ of the sale and the second only $58,35 \%$. Men's health and gastroin- 
testinal medicines were validated at $5 \%$ significance, being $76,36 \%$ of first category sales expressed by the model and $80,37 \%$ for the second.

Table 6 - Medicines with correlation for temperature

\begin{tabular}{llllllllll}
\hline & \multicolumn{1}{l}{ Coefficient } & \multicolumn{5}{c}{ Statistic } \\
\cline { 2 - 10 } & Constant & Avg. Sale & Precipitation & Prob. & Avg. Temp. & Prob. & $R^{2}$ & Prob. F & $\begin{array}{l}\text { Durbin } \\
\text { Watson }\end{array}$ \\
\hline $\begin{array}{l}\text { Nervous } \\
\text { system }\end{array}$ & $6.521,34$ & 0,3549 & - & - & $-20,8899$ & 0,0006 & $82,16 \%$ & 0,0000 & 2,1349 \\
\hline $\begin{array}{l}\text { Circulatory } \\
\text { system }\end{array}$ & $1.048,32$ & 0,1358 & - & - & 5,7130 & 0,0003 & $58,35 \%$ & 0,0000 & 2,0379 \\
\hline Men's health & $1.058,56$ & 0,3525 & - & - & $-3,1082$ & 0,0104 & $76,37 \%$ & 0,0000 & 2,1601 \\
\hline Gastro & $2.090,27$ & 0,6073 & - & - & 5,0270 & 0,0323 & $80,37 \%$ & 0,0000 & 2,2508 \\
\hline
\end{tabular}

Source: Prepared by the authors (2021).

The sign (positive or negative) of the temperature coefficient indicates what kind of effect that the variable will have over sales, with the direction and intensity observed through the Figure 10. Nervous system and men`s health model indicates that temperature has a negative effect on sales of these types of medicines, it is also possible to observe through the inclinations of the lines that the intensity of this effect in the first category is greater. With lower intensity, gastro and circulatory system indicate that a higher temperature results in higher sales of this type of product.

Figure 10 - Single correlation model for temperature

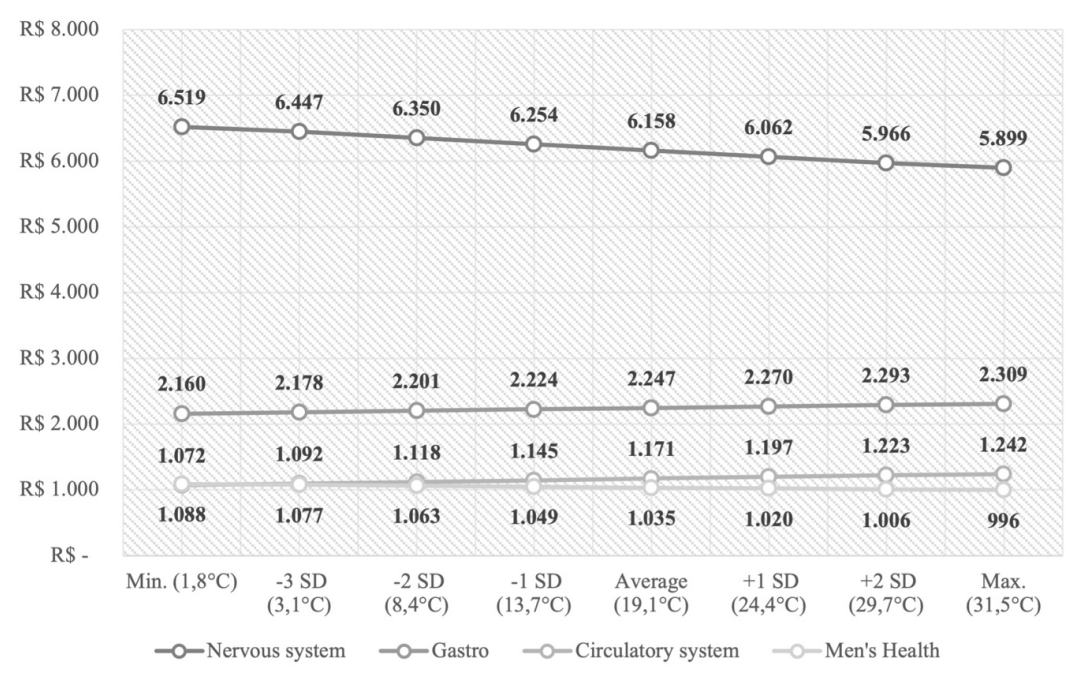

Source: Prepared by the authors (2021). 
On the other hand, four other categories presented correlation only for precipitation, the results can be seen in table 7 . Heart system model, with a significance of $1 \%$, can explain $85 \%$ of sales in this category, while other models for cholesterol, diabetes and women `s health were validated at $5 \%$ of significance, they are able to explain $88,82 \%, 73,73 \%$ and $79,92 \%$ of the sales respectively.

Table 7 - Medicines with correlation for precipitation

\begin{tabular}{llllllllll}
\hline & \multicolumn{1}{l}{ Coefficient } & \multicolumn{4}{c}{ Statistic } \\
\cline { 2 - 10 } & Constant & Avg. Sale & Precipitation & Prob. & $\begin{array}{l}\text { Avg. } \\
\text { Temp. }\end{array}$ & Prob. & $\mathrm{R}^{2}$ & Prob. F $\begin{array}{l}\text { Durbin } \\
\text { Watson }\end{array}$ \\
\hline Heart System & $1.524,88$ & 0,7906 & $-1,6222$ & 0,0001 & - & - & $85,64 \%$ & 0,0000 & 2,331 \\
\hline Cholesterol & 509,18 & 0,8407 & $-0,6780$ & 0,0040 & - & - & $88,82 \%$ & 0,0000 & 2,5630 \\
\hline Diabetes & $1.413,46$ & 0,5460 & $-0,6021$ & 0,0298 & - & - & $73,73 \%$ & 0,0000 & 2,3025 \\
\hline Women's health & $2.432,99$ & 0,5651 & $-0,8425$ & 0,0105 & - & - & $79,92 \%$ & 0,0000 & 2,2703 \\
\hline
\end{tabular}

Source: Prepared by the authors (2021).

Just as when they appear simultaneously with another variable, precipitation always has a negative effect on sales. This behavior can be explained by the difficulty in rainy days to shop, as already presented in the literature review. Anyway, the intensity of this phenomenon is observed differently for each category, as we can see in figure 11, where women`s health and hearth system present the largest negative slope.

Figure 11 - Single correlation model for precipitation

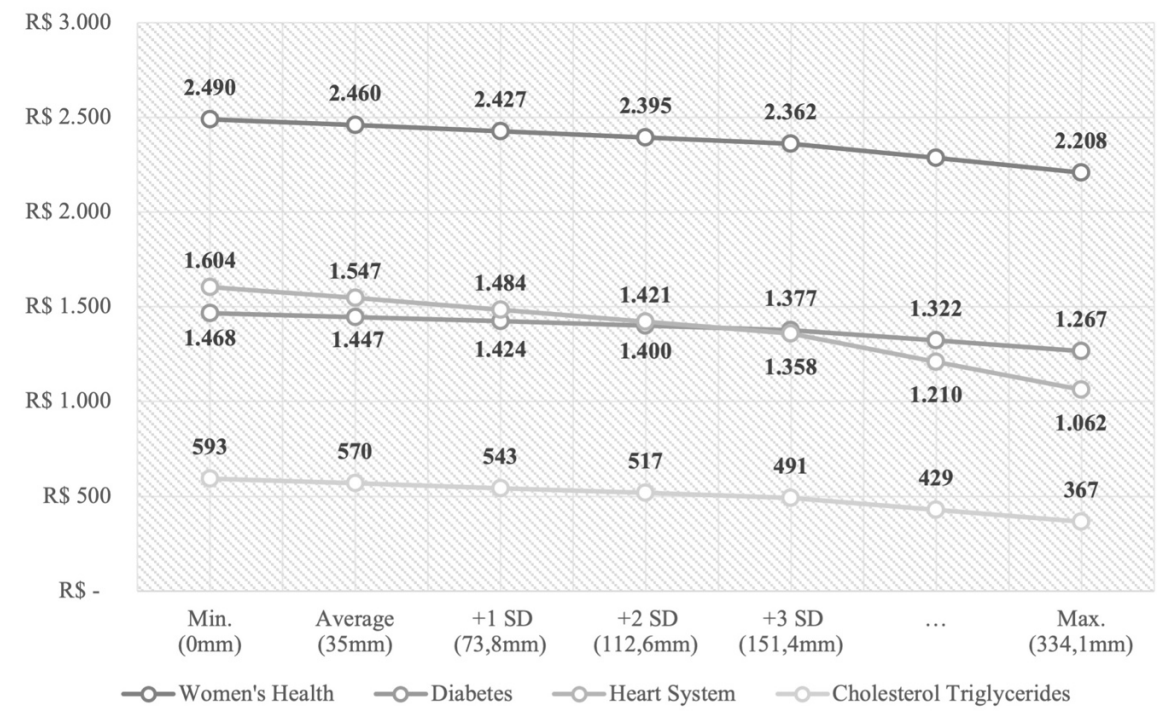

Source: Prepared by the authors (2021). 
Among 19 categories of medicines analyzed in this study, 16 presented some type of influence of climatic variables on the sales pattern. Meanwhile, medications for the treatment of weight loss, oncological and endocrine showed no significant correlation between climatic variables and the pattern of sales. There are some exogenous factors that may explain the absence of correlation for most categories, among them the need for continued use of many drugs for certain treatments, of great importance mainly for chronic and degenerative diseases such as hypertension, diabetes or health problems population aging.

\section{Conclusion}

This article aimed to analyze the impact of climatic variables on the sale of drugs in the southern region of Brazil during the period from January 2012 to June 2016. The main hypothesis tested in this study, that climatic variables have a significant effect on sales, could be confirmed for some categories of medicines, with different influences between them. From a total of 19 categories analyzed, eight showed a correlation in sales simultaneously between temperature and precipitation, four only for temperature and other four only for precipitation, just three categories do not present significant correlation for any climatic variable.

For the categories where the correlation was detected, it is possible to highlight medications for allergies, infections and flus, it is estimated that sales increase on the coldest days, when people spend the most time indoors, facilitating spread of viruses and other infectious problems. For contusion medicines the result found was the opposite, the sales grow in the hottest weeks, probably the time where people are more willing to practice physical activities. For the categories that did not present correlation, one of the possible interpretations is the need for continued use of many drugs for certain treatments, of great importance mainly for chronic and degenerative diseases such as hypertension, diabetes or health problems population aging.

To reach these results, some difficulties had to be overcome, such as the existence of external factors and difficult to measure, such as promotional actions, migratory effect between regions and other changes in demand not related to the variables addressed. Second point, the existence of diverse seasonality throughout the panel, such as lower demand on Sundays and holidays, festive seasons, holidays, paydays and Christmas. Third, the difficulty in finding available data for the panel's elaboration, few public data have regional segmentation or with the necessary periodicity. Therefore, the contribution of this study is firstly applied to pharmaceutical retailing and observation of the regional behavior of the sale of medicines, after which various articles and academic studies have been found on the subject, but in other areas or regions. 
Finally, it is possible to conclude that rain and temperature are two significant variables and exert a direct influence on the sales behavior of some categories of medicines, so it is essential to include them in the calculation of the demand of the sector for better management of purchases, inventories and decrease of losses due to excess and overdue. There is also the possibility of evolving the theme in studies for the creation of new economic tools, such as climate insurance, with the purpose of protecting mainly small industry and retail, more susceptible to the effects of the climate due to its regional performance.

From the climate data point of view, there would be no restriction or limitations for extrapolation data, it would be advisable only to carry out a pilot test, matching the values found. Considering the transactional sales panel, the study is limited only the establishments where the data were collected, even if it presents statistical consistency. The limitation of the analysis occurs because it is not possible to guarantee the homogeneous or equivalent behavior of the data in establishments where the study was not carried out, this because the sample does not represent the total sales, only a portion of the market and that behaves of determined way. Therefore, extrapolation of results to establishments, cities or circumstances not observed are not recommended. On the other hand, the model presented throughout the study can easily be used for the development of new studies and researches.

\section{References}

BEAUCHAMP, J. J.; DOWNING, D. J.; RAILSBACK, S. F. Comparison of regression and time-series methods for synthesizing missing streamflow records. Journal of the American Water Resources Association, v. 25, n. 5, p. 961-975, 1989.

BERNANKE, B. S.; FRANK, R.H. Princípios de economia. 4. ed. São Paulo: Mc Graw Hill, 2009.

BARROS, M. E. D. O controle social e o processo de descentralização dos serviços de saúde. Brasília: IEC, 1995.

BRITO, P. S.; BARROS, F. M. Aquisição de medicamentos: um paralelo entre a compra e o desperdício dos medicamentos adquiridos pelo setor público. Saúde E Ciência em Ação, v. 1, n. 1, p. 57-71, 2015.

CAMARGO, M. B. P. et al. Estimativa da produtividade potencial de cultivares de soja nas condições climáticas de Ribeirão Preto, SP, Bragantia, v. 47, n. 2, p. 277-288, 1988.

GUJARATI, D.; PORTER, D. Econometria básica. 5. ed. São Paulo: Mc Graw Hill, 2011.

HENDRY, D. F. Dynamic econometrics. Nova York: Oxford University Press, 1995. 
KOTLER, P.; KELLER, K. L. Administração de marketing. 12. ed. São Paulo: Person, 2006.

LARSEN, P. H. An Evaluation of the sensitivity of U.S. Economic sectors to weather. Stanford: Lawrence Berkeley National Laboratory, 2006.

LEVY, M. et al. Retailing management. Nova York: Mc Graw Hill, 2012.

MARGULIS, S. et al. Economia da Mudança do Clima no Brasil. São Paulo: IBEP, 2010.

MASON, J. B.; MAYER, M. L.; WILKINSON, J. B. Modern Retailing: Theory and practice. 6. ed. Illinois: Irwin, 1993.

SOLOMOU, S.; WU, W. Weather effects on european agricultural output. Cambridge: Cambridge University Press, 1999.

STARR-MCCLUER, M. The effects of weather on retail sales. Washington: Federal Reserve Board of Governors, 2000.

STEELE, A. T. Weather's effect on the sale of a department store. Journal of Marketing, v. 15, n. 4, p. 436-443, 1951.

TOL, R. S. J. weather impacts on natural, social, and economic systems in the Netherlands. Amsterdam: Institute for Environmental Studies, 2000.

VEBLEN, T. The theory of the leisure class. New York: Macmillan, 1899

\section{Autor correspondente:}

Pedro Brandão Dalla Valle

E-mail: pedro.bdv@gmail.com

Recebido em: 13/09/2018.

Aceito em: 13/01/2020.

\section{(cc) BY}

\footnotetext{
Este é um artigo de acesso aberto distribuído sob os termos da Creative Commons Attribution CC-BY 4.0, que permite uso irrestrito, distribuição e reprodução em qualquer meio, desde que o trabalho original seja devidamente citado.
} 